\title{
Color-based Segmentation of Batik Using the L*a*b Color Space
}

\author{
Anita Sindar Sinaga \\ STMIK Pelita Nusantara : Informatics Engineering \\ Medan, Indonesia \\ haito_ita@yahoo.com
}

\begin{abstract}
Indonesian Batik has a variety of styles. Coloring techniques affect the color quality of batik. Color is very important to show staining breakthroughs. The colors R (Red) G (Green) and B (Blue) have a close color correlation level so that it is difficult to segment. Segmentation is the process of partitioning digital images into several segments. The segmentation process is carried out on 15 batik sample data. The first step, each sample is converted from RGB - XYZ - Lab color. The average ratio of Red, Green and Blue on the RGB color and XYZ color 1:10. Segmentation using L*a*b color, displays the composition of the sample data colors into six clusters: background, yellow, magenta, purple, red and green using the clustering method. This proposed work $\mathrm{L}^{*} \mathrm{a} * \mathrm{~b}$ color space is selected which is a homogeneous space for visual perception.
\end{abstract}

Keywords—RGB; XYZ; L*a*b Color Space; Segmentation; Clustering

\section{INTRODUCTION}

Batik colors tend to have a mixture of the same color components. Derived from a mixture of primary colors Red Green and Blue. Problems often arise in terms of claims for batik products. When each batik is made detailed information from giving names, patterns, batik materials, and one of them is the color composition component of batik. To get batik color details, batik digital color segmentation can be done. Segmentation with $\mathrm{L} * \mathrm{a} * \mathrm{~b}$ color produces detailed colors, in addition to the commonly seen colors. $\mathrm{L}^{*} \mathrm{a} * \mathrm{~b}$ color produces a division of 6 color regions. A Lab colour space is a colour opponent space with dimension $\mathrm{L}$ for lightness and $\mathrm{a}$ and $\mathrm{b}$ for the colouropponent dimensions, based on nonlinearly compressed CIE XYZ colour space coordinates. "Lab" colour spaces is to create a space which can be computed via simple formulas from the $\mathrm{XYZ}$ space, but is more perceptually uniform than XYZ.

The batik coloring technique undergoes innovation to produce a variety of attractive colors. Ombre technique (moonlight) is used to fill the void or blur in the motif without changing the grip. Garaman technique is mixing natural colors with chemistry aimed at getting different effects so as to produce unexpected colors, chemical textile techniques

describe the process of performance of ink sprays issued by printing machines. Batik printing or batik screen printing is made through a manual screen printing process or a factory printing machine. Digital textile printer machines or digital printing cloths are machines for printing fabrics [1].

Digital color matching is done at the preprocessing stage to produce attractive colors. Segmentation is the process of partitioning a digital image into several segments (Pixel sets) aiming to simplify and / or change the presentation of images to something more meaningful and easier to analyze. The segmentation process separates the foreground region from the background region to simplify and / or change the presentation of images to something more meaningful and more [2]. The process of batik cloth color segmentation is done using $\mathrm{L}^{*} \mathrm{a} * \mathrm{~b}$ color space based on color features [3]. The CIELAB color space expresses colours as three numeric values, $\mathrm{L} *$ for light levels and $\mathrm{a} *$ and $\mathrm{b} *$ for green-red and blue-yellow components [4]. This color space is able to describe all colors that can be seen with the human eye and is often used as a color space reference. Numerical comparisons between color samples and standards show differences in color coordinates (Delta, $\Delta$ ). To start, the color of the sample and the standard color are measured and the measurement value is observed. The color difference between the sample and the standard is calculated using the colorimetric value produced. This calculation shows the difference between two colors to identify inconsistencies and help users control product colors more effectively [5]. 


\section{REVIEW OF LITERATURE}

\section{$L * a * b$ Colors}

The three coordinates of LAB represent the lightness of the color $\left(\mathrm{L}^{*}=0\right.$ yields black and $\mathrm{L}^{*}=100$ indicates diffuse white; specular white may be higher), its position between red/magenta and green ( $a^{*}$, negative values indicate green while positive values indicate magenta) and its position between yellow and blue $\left(b^{*}\right.$, negative values indicate blue and positive values indicate yellow) coordinate ranges from 0 to 100. A Lab colour space is a colour opponent space with dimension $\mathrm{L}$ for lightness and $\mathrm{a}$ and $\mathrm{b}$ for the colouropponent dimensions, based on nonlinearly compressed CIE XYZ colour space coordinates. "Lab" colour spaces is to create a space which can be computed via simple formulas from the XYZ space, but is more perceptually uniform than XYZ [6], [7].

\section{Image segmentation}

Image segmentation is a process that is intended to get objects contained in the image or divide the image into several regions with each object or region having similar attributes. image segmentation techniques are based on two basic properties of gray level values: discontinuities and similarities between pixels. In the first form, image separation is based on sudden changes in the gray level [8].

Regional segmentation is an advanced approach to edge detection. In edge detection of image segmentation is done through identification of object boundaries (boundaries of object). Limits are locations where there is a change in intensity. Clustering is used as a segmentation technique using uniform predicates. Segments that are generated from cluster clustering are usually called clusters.

There are various segmentation techniques, all of which are classified into 2 types based on how they work, namely:

1. Segmentation based on color intensity.

2. Segmentation based on color characteristics.

Assume that the objects to be separated tend to have different color intensities and each object has a nearly uniform color. One of the segmentation techniques based on color intensity is mean clustering. At the mean the image is divided by dividing the image histogram.

Following are the steps [9]:

1. Look for the maximum and minimum intensity used in the image.

2. From the minimum intensity to the maximum number of $\mathrm{N}$ is done. $\mathrm{N}$. This determines the number of objects expected in the picture.

3. After division, histograms are divided into sections called clusters (groups). Then in the image search for all points, each point will be grouped into the closest cluster so that the end result of this process is the number of colours in the image to be $\mathrm{N}$.

4. Find the results of the average / mean of all points in each cluster, then change the color of all points in the clusters with the average of each cluster.

\section{Clustering}

A cluster is a unit of values within a certain distance at a certain distance (relatively large) compared to the density of values surrounding area. Clustering process [10]:

1. Set data set of algorithms to use (KMeans), that is by taking random value of $\mathrm{k}$.

2. RGB appearance of each pixel created, and produces a dataset in 3 vector.

3. The K-Means algorithm is applied to the dataset, establish center clustering $\mathrm{k}$. KMeans algorithm will present $\mathrm{k}$ colors for describe the image.

4. Each pixel of the image is converted in one vector RGB line, and displayed using the average of the color groups produced.

K-Means algorithm process:

1. Existing data is separated in groups data (cluster) $\mathrm{k}$ and data values randomized into the results of the inner data group data groups that have similar numbers from the data value.

2. Each data value is calculated using distance Euclidean for each cluster.

3. If the data value is represented by a separate data group, leave it, and if the value of the data is not represented by data group, move into the data group who have been represented.

4. Repeat the steps above to complete all results of data values in displacement one cluster to other clusters.

Some previous studies that discussed segmentation using $\mathrm{L}^{*} \mathrm{a} * \mathrm{~b}$ color space : Effect of color space on color image segmentation, the title explain a segmentation procedure based on maxi-mizing the information contents in the segmented foregroundand background objects will be presented. Colour based image segmentation using $\mathrm{L}^{*} \mathrm{a} * \mathrm{~b}$ colour space based on genetic algorithm, this title explain about colours which means that its gamut exceeds those of the RGB and CMYK colour models. One of the most important attributes.

\section{METHODOLOGY}

The nonlinear relations for $\mathrm{L}^{*}, \mathrm{a}^{*}$, and $\mathrm{b}^{*}$ are intended to mimic the nonlinear response of the eye. Furthermore, uniform changes of components in the $\mathrm{L}^{*} \mathrm{a} \mathrm{b}^{*}$ color space aim to correspond to uniform changes in perceived color, so the relative perceptual differences between any two colors in $\mathrm{L}^{*} \mathrm{a} \mathrm{b}^{*}$ can be approximated by treating each color as a point in a three 
dimensional space (with three components: $L^{*}, a^{*}, b^{*}$ ) and taking the Euclidean distance between them.

Color space (or sometimes called a color system or color model) as a coordinate system specification and a subspace in the system with each color expressed with a single point in it. The purpose of the formation of color space is to facilitate the specification of colors in the form of a standard. Color space RGB (Red, Green, Blue) is a primary color combination of red, green, and blue, which is commonly used by computer monitors or televisions. The resulting color comes from a combination of three colors and each has a value of 8 red bits, 8 green bits, and 8 blue bits.

Batik samples taken randomly consist of 15 types of batik in the form of digital images. regardless of the origin and typical of batik. Samples are selected from batik colors that have similar colors to bright colors. Limit sample data to maximize color identification results. Identifying batik color components starting with RGB color conversion - XYZ produces value of L, value $a$, value $b$.The systematics in this study applies color feature extraction using color-based image segmentation using $\mathrm{L}^{*} \mathrm{a} * \mathrm{~b} *$ color, Fig 1:

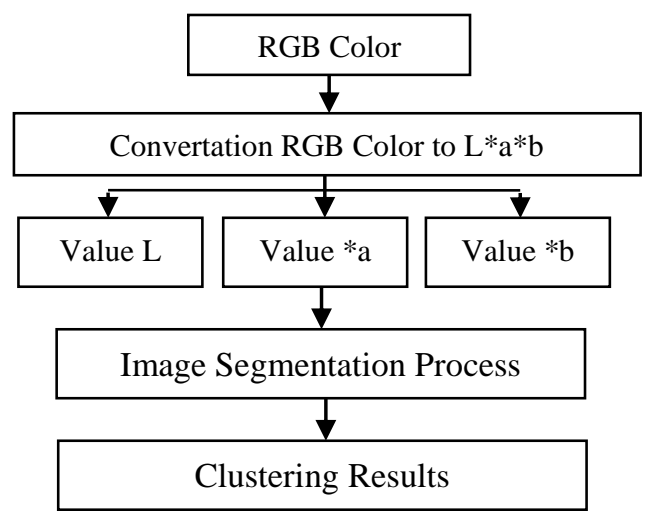

Fig. 1. Systematic Research

Segmentation using the RGB to Lab transforms works well with identifying marks on the foreground locations. The basic procedure is as follows.

1. The color is transformed from RGB to Lab color space for the input image.

2. Read in the gradient magnitude as the segmentation function.

3. Dimensions are split.

4. Reshaping is done with respect to the colors.

5. The colors are clustered and border pixels are fixed in a matrix.

6. Modify the segmented function so that it only has minima at the foreground and background marker locations.

7. Visualize the result,
RGB values contained in a pixel can be transformed into CIE XYZ color space through a $3 \times 3$ matrix transformation process. This transformation involves tristimulus values, which is an arrangement of three light-linear components that fulfill the CIE color matching function. In the XYZ color space, some colors are represented as always positive values. The segmentation process is done by dividing the image matrix data $\mathrm{L} * \mathrm{a} * \mathrm{~b} *$ into 6 color sections.

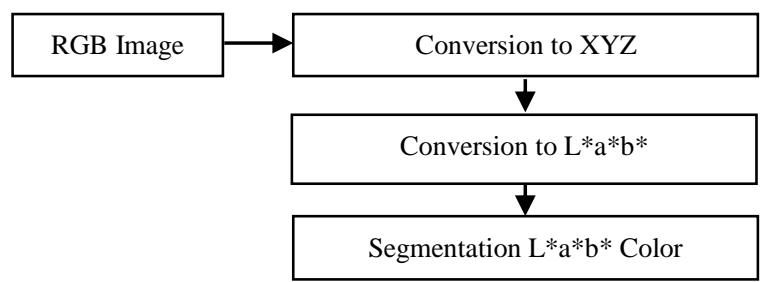

Fig. 2. Segmentation $L * a * b$ Color Process

The color management system uses the Lab as a color reference for predictable changes, a form of color from one color space to another color space. The lab describes color in relation to luminance or lightness components (L) and two chromatic components (a), red and green components and (b) components (yellow and blue).
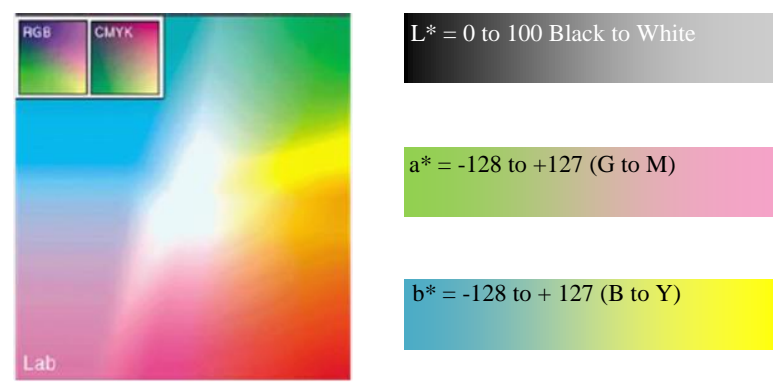

Fig. 3. The Lab Model Color

\section{RESUlT AND DisCUSSION}

Batik samples taken from various digital images of batik totaling 15 batik. Each batik counts RGB values based on the value of the batik matrix. Color-based segmentation stages using $\mathrm{L}^{*} \mathrm{a} * \mathrm{~b}$ color space:

1. Image of batik file format .jpg. Resizing images is done to facilitate image extraction.
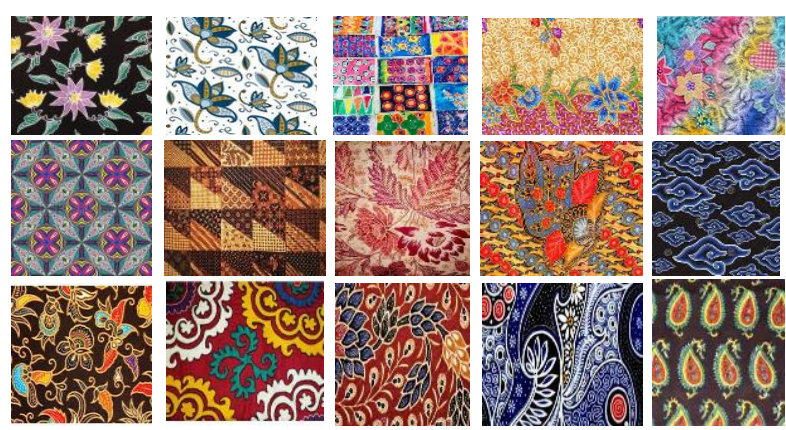
Fig. 4. Image of Batik

2. Calculation transformation RGB Color to L*a*b*:

$$
\begin{aligned}
& X=0,412453 R+0,357580 G+0,180423 B . \\
& Y=0,212671 R+0,715160 G+0,072169 B . \\
& Z=0,019334 R+0,119193 G+0,950227 B .
\end{aligned}
$$

Starting convertation RGB value to $\mathrm{XYZ}$ value result, Trials with 15 batik patterns. Table 1:

TABLE 1 CONVERSION RGB TO XYZ RESULT

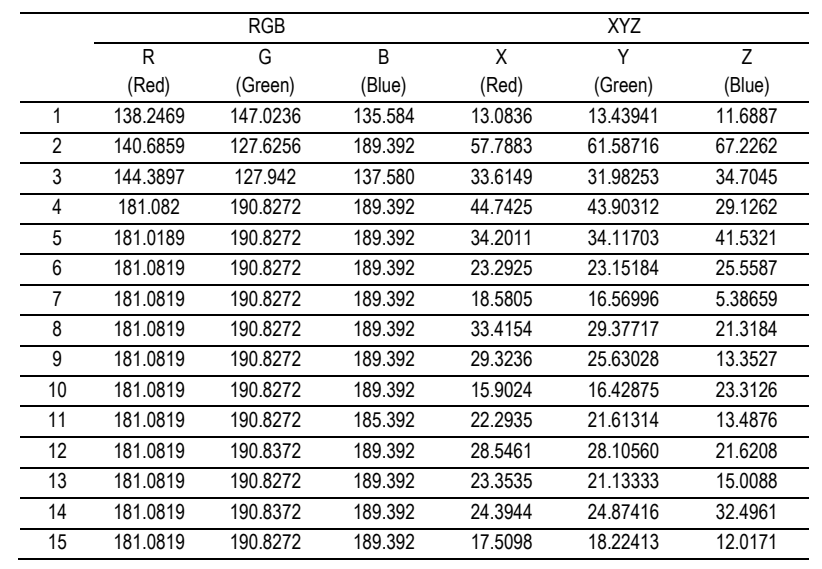

Color space conversion is the translation of the representation of a color from one basis to another. This typically occurs in the context of converting an image that is represented in one color space to another color space, the goal being to make the translated image look as similar as possible to the original. The $X Y Z$ color uses three filters X (red), Y (green), and Z (blue), XYZ image result, Fig 5:
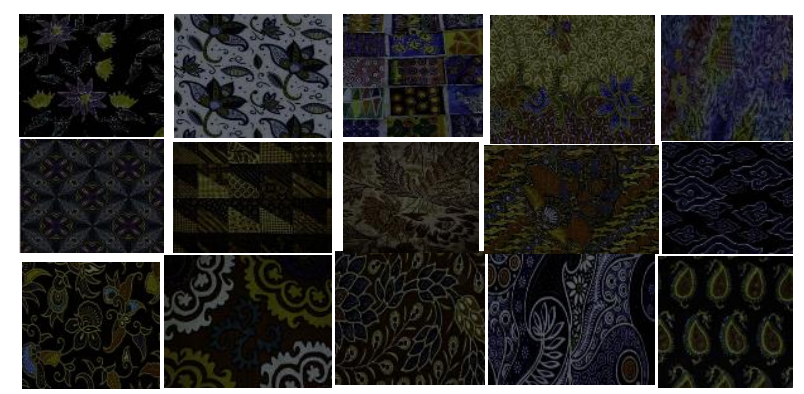

Fig. 5. XYZ Image Result

$\mathrm{L}^{*} \mathrm{a} \mathrm{b}^{*}$ defined:

$$
\begin{aligned}
& \mathrm{L}^{*}=116 \mathrm{f}\left(\frac{\mathrm{y}}{\mathrm{y}_{\mathrm{n}}}\right)-16 \ldots \ldots \ldots \ldots \ldots . . .(4) \\
& \left.\mathrm{a}^{*}=500 \mathrm{f}\left(\frac{\mathrm{x}}{\mathrm{x}_{\mathrm{n}}}\right)-\mathrm{f}\left(\frac{\mathrm{y}}{\mathrm{y}_{\mathrm{n}}}\right)\right] \ldots \ldots .(5 \\
& \mathrm{b}^{*}=200\left[\mathrm{f}\left(\frac{\mathrm{x}}{\mathrm{x}_{\mathrm{n}}}\right)-\mathrm{f}\left(\frac{\mathrm{z}}{\mathrm{z}_{\mathrm{n}}}\right)\right] \ldots \ldots .(6
\end{aligned}
$$

$\mathrm{Xn}, \mathrm{Yn}$, and $\mathrm{Zn}$ are respectively corresponding to the white value of the parameter.

$$
f(x)=\left[\begin{array}{lr}
X 1 / 3 & x>0.008856 \\
7.787 x+16 / 116 x<=0.008856
\end{array}\right] \ldots \ldots
$$
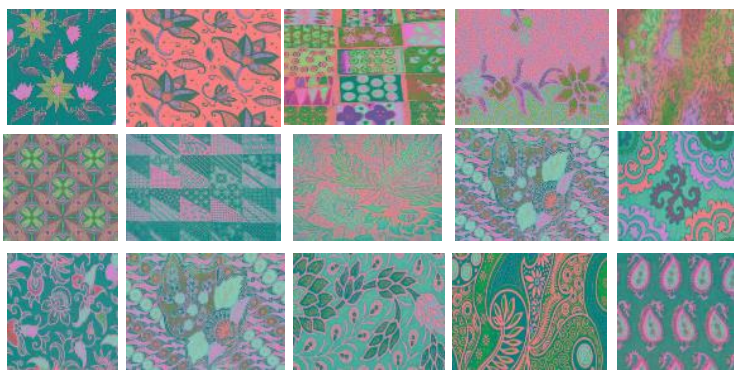

Fig. 6. Convertation L*a*b* Color Result $\mathrm{L}^{*}$ showing Light, $\mathrm{a}^{*}$ : red / green, $\mathrm{b}^{*}$ : yellow / blue. Delta / difference $\mathrm{L}^{*}\left(\Delta \mathrm{L}^{*}\right), \mathrm{a}^{*}\left(\Delta \mathrm{a}^{*}\right)$ dan $\mathrm{b}^{*}\left(\Delta \mathrm{b}^{*}\right)$ can positive (+) or negative (-). Total difference, Delta $\mathrm{E}$ $\left(\Delta \mathrm{E}^{*}\right)$, always positive, Fig. 6. Trial of batik 1 sample, using the clustering method, Fig. 7.
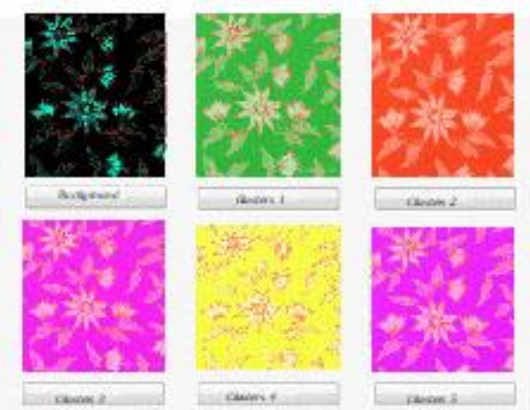

Fig. 7. Segmentation L*a*b* Color

Comparison of 1: 10 is obtained from the average conversion of RGB values - XYZ color. Result comparison graph Red (RGB) : Red (XYZ), Green (RGB) : Green (XYZ), Blue (RGB) : Blue (XYZ) for 15 batik image sample, Fig. 8 . 


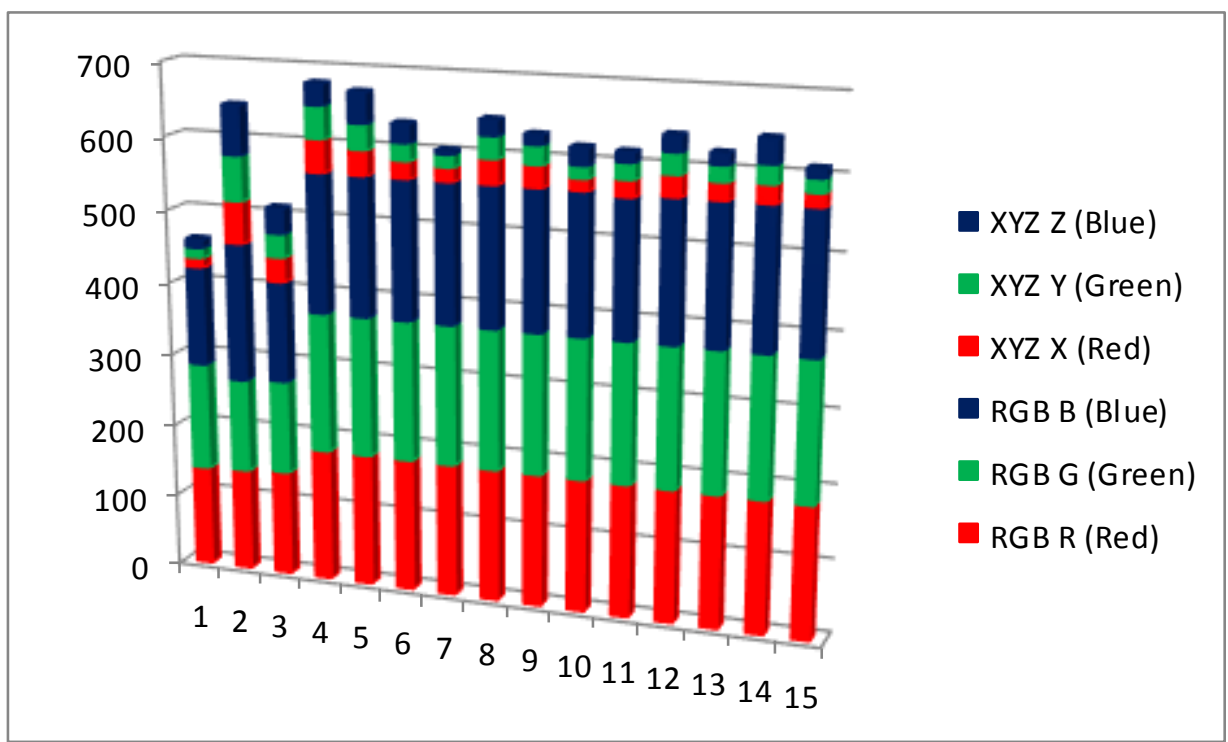

Fig. 8. Comparison Red (RGB) : Red (XYZ), Green (RGB) : Green (XYZ), Blue (RGB) : Blue (XYZ)

\section{CONCLUSION}

1. The RGB value of a pixel can be transformed into the CIE XYZ color space through the process of calculating the values of $R, G$ and $B$. Color transformation of $\mathrm{XYZ}-\mathrm{L}^{*} \mathrm{a} * \mathrm{~b}$ color space produces homogeneous colors in the same region.

2. The XYZ color uses three filters $X$ (Red), $Y$ (Green), and $\mathrm{Z}$ (Blue), Comparison of the values of Red, Green and Blue on the average RGB - XYZ color conversion result of $1: 10$. Primary colors dominate the color composition of batik. The XYZ color component contains an RGB color, on Fig. 8, compared the initial RGB value of the image with the results of the RGB value that is in the XYZ color conversion.

\section{ACKNOWLEDGMENT}

Big thank for the support of LPPM Penusa.

\section{REFERENCES}

[1] Miftahus Sholihin, Siti Mujilahwati, Retno Wardhani "CLASSIFICATION OF BATIK LAMONGAN BASED ON FEATURES OF COLOR, TEXTURE AND SHAPE", Jurnal Ilmiah Kursor, Vol. 9, No.1, pp. 25-32, Juli 2017.

[2] K. Kavi Niranjana, M. Kalpana Devi, "RGB to Lab Transformation Using Image Segmentation", International Journal of Advance Research in Computer Science and Management StudiesVolume 3, I ssue 11, pg. 8-16, November 2015.

[3] Dibya Jyoti Bora, Anil Kumar Gupta, Fayaz Ahmad Khan, "Comparing the Performance of $\mathrm{L}^{*} \mathrm{~A}^{*} \mathrm{~B}$ * and HSV Color Spaces with Respect to Color Image Segmentation", Volume 5, Issue 2, pp. 192-203, February 2015.
[4] Sukmawati Nur Endah, Retno Kusumaningrum, Helmie Arif Wibawa, "Color Space to Detect Skin Image: The Procedure and Implication", Scientific Journal of Informatics, Vol. 4, No. 2, pp. 143-149, November 2017.

[5] Mohammad A. Al-Jarrah, "Image Segmentation Utilizing Color-Space Feature", International Journal of Multimedia Data Engineering and Management, 6(1), 39-53, JanuaryMarch 2015.

[6] P. Ganesan, V. Rajini, B. S. Sathish, V. Kalist, S. K. Khamar Basha, "Satellite Image Segmentation Based on YCbCr Color Space", Indian Journal of Science and Technology, Vol 8(1), 35-41, January 2015.

[7] Ramaraj.M, S.Niraimathi, "APPLICATION OF COLOR BASED IMAGE SEGMENTATION PARADIGM ON RGB COLOR PIXELS USING FUZZY C-MEANS AND K MEANS ALGORITHMS", International Journal of Computer Science and Mobile Computing, Vol.6 Issue.6, pg. 430-440, June- 2017.

[8] Khushbu Raval Ravi Shukla and Ankit KShah "Color Image Segmentation using FCM Clustering Technique in RGB L*a*b, HSV, YIQ Color spaces", European Journal of Advances in Engineering and Technology, 4 (3):194-200, 2017.

[9] Md. Rakib Hassan, Romana Rahman Ema \& Tajul Islam "Color Image Segmentation using Automated K-Means Clustering with RGB and HSV Color Spaces", Global Journal of Computer Science and Technology: Graphics \& vision, Volume 17 Issue 2, January 2017.

[10] Neelambike S, Parashuram Baraki, "Color Image Segmentation By Clustering", International Journal of Advanced Research in Computer Science \& Technology (IJARCST 2014), Vol. 2 Issue 1 95-97, Jan-March 2014. 